\title{
Mechanisms and Machine Science
}

\author{
Volume 40
}

Series editor

Marco Ceccarelli

Laboratory of Robotics and Mechatronics

University of Cassino and South Latium

Cassino, Italy 
More information about this series at http://www.springer.com/series/8779 
Antonio Simón Mata - Alex Bataller Torras Juan Antonio Cabrera Carrillo

Francisco Ezquerro Juanco

Antonio Jesús Guerra Fernández

Fernando Nadal Martínez

Antonio Ortiz Fernández

\section{Fundamentals of Machine Theory and Mechanisms}

望 Springer 

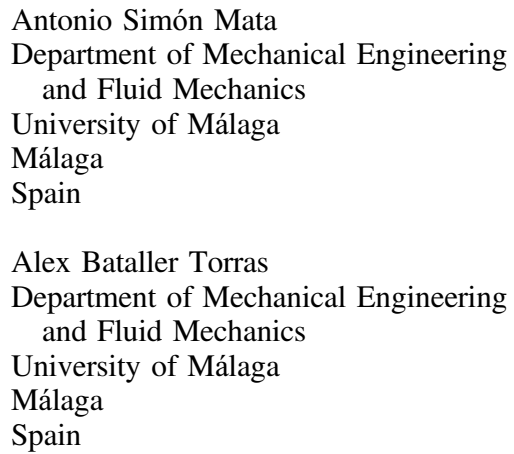

Juan Antonio Cabrera Carrillo

University of Málaga

Málaga

Spain

Francisco Ezquerro Juanco

University of Málaga

Málaga

Spain

\author{
Antonio Jesús Guerra Fernández \\ University of Málaga \\ Málaga \\ Spain
}

Fernando Nadal Martínez

University of Málaga

Málaga

Spain

\section{Antonio Ortiz Fernández}

University of Málaga

Málaga

Spain
ISSN 2211-0984

Mechanisms and Machine Science

ISBN 978-3-319-31968-1

DOI 10.1007/978-3-319-31970-4

Library of Congress Control Number: 2016938648

(C) Springer International Publishing Switzerland 2016

Translation from the Spanish language edition: Fundamentos de Teoría de Máquinas by Simón Mata, Antonio, (C) Bellisco 2000. All rights reserved

This work is subject to copyright. All rights are reserved by the Publisher, whether the whole or part of the material is concerned, specifically the rights of translation, reprinting, reuse of illustrations, recitation, broadcasting, reproduction on microfilms or in any other physical way, and transmission or information storage and retrieval, electronic adaptation, computer software, or by similar or dissimilar methodology now known or hereafter developed.

The use of general descriptive names, registered names, trademarks, service marks, etc. in this publication does not imply, even in the absence of a specific statement, that such names are exempt from the relevant protective laws and regulations and therefore free for general use.

The publisher, the authors and the editors are safe to assume that the advice and information in this book are believed to be true and accurate at the date of publication. Neither the publisher nor the authors or the editors give a warranty, express or implied, with respect to the material contained herein or for any errors or omissions that may have been made.

Printed on acid-free paper

This Springer imprint is published by Springer Nature

The registered company is Springer International Publishing AG Switzerland 


\section{Preface}

This book is the result of many years of experience teaching kinematics and dynamics of mechanisms at Malaga University. The compilation of different class notes resulted in the first book by the authors in 2000. Along the last years, five improved editions have been printed, all of them only available in Spanish. At present, many universities in Spain and Latin America use this book as a teaching support.

In this first edition in English, we have included those chapters that we think are essential in a Theory of Mechanisms and Machines course. Instead of following a rigid order per topic, the chapters have been organized the main goal being to present the contents in a fluid way, trying not to cut the rhythm of the development. So, the first part completely develops the kinematic and dynamic analysis of linkages. Then, it continues with dynamics, studying flywheels and vibrations in systems with one degree of freedom. Back to kinematics, it studies the transmission of motion with gears. Finally, it presents the main concepts of the synthesis of mechanisms as well as the latest techniques in this field, such as an optimization method based on evolutionary algorithms and a new method to measure the error between two curves based on turning functions. Several examples are included to compare the results obtained following different synthesis methods.

At the end of the book, there are three addendums that complete the concepts developed in some of the chapters and that help the student to assimilate them. The first addendum develops the trigonometric method for the position analysis of different linkages. The second one includes Freudenstein's method applied to the resolution of Raven's position equations in a four-bar linkage. Finally, the last addendum solves the kinematic and dynamic analysis of a six-link mechanism using different methods explained in this book.

Because of its educational focus, we have included some graphical methods in this book. Although, nowadays, the use of analytical methods is basic in Theory of Mechanisms and Machines, according to our experience, the didactic aspect of 
graphical methods is unquestionable. Therefore, we use them at the beginning of the kinematic and dynamic analysis of linkages. This helps to consolidate new concepts and to better understand the behavior of mechanisms. Then, once this has been achieved by the student, modern and powerful analytical methods are developed. 


\section{Contents}

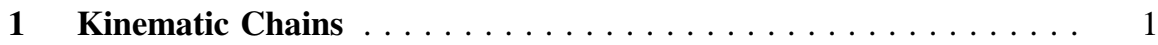

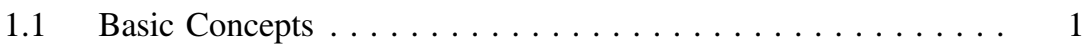

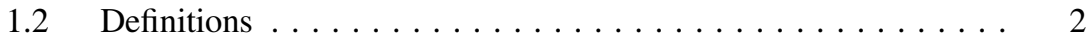

1.2.1 Degrees of Freedom (DOF) . . . . . . . . . . . 2

1.2.2 Links and Kinematic Pairs . . . . . . . . . . . 3

1.2.3 Classification of Kinematic Pairs ........... 3

1.2.4 Kinematic Chains, Mechanisms, Kinematic Skeletons and Machines .................. 5

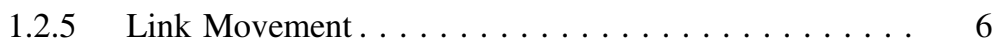

1.3 Degrees of Freedom of Mechanisms. . . . . . . . . . . 8

1.3.1 Fixed Mechanisms. Structures . . . . . . . . . . . . 9

1.3.2 Mechanisms with One DOF . . . . . . . . . . 10

1.3.3 Mechanisms with More Than One DOF ......... 12

1.4 Kinematic Inversions . . . . . . . . . . . . . . . . . 13

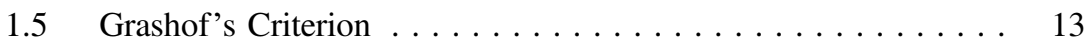

1.6 Mechanical Advantage . . . . . . . . . . . . . . . 15

1.7 Kinematic Curves . . . . . . . . . . . . . . . . . 16

1.7.1 Application of Different Mechanisms with Different Purposes...................... 18

2 Kinematic Analysis of Mechanisms. Relative Velocity

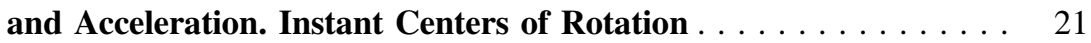

2.1 Velocity in Mechanisms ................... 21

2.1.1 Position, Displacement and Velocity of a Point ..... 21

2.1.2 Position, Displacement and Angular Velocity

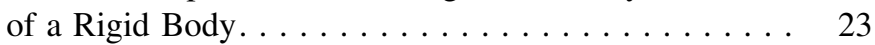

2.1.3 Relative Velocity Method ............... 25

2.1.4 Instant Center of Rotation Method . . . . . . . . . . . 45

2.2 Accelerations in Mechanisms................ 55

2.2.1 Acceleration of a Point . . . . . . . . . . . . 56

2.2.2 Relative Acceleration of Two Points. . . . . . . . . 58 
2.2.3 Relative Acceleration of Two Points in the Same Rigid Body . . . . . . . . . . . . . . . . 60

2.2.4 Computing Acceleration in a Four-Bar Linkage . . . . . . . 62

2.2.5 The Coriolis Component of Acceleration. . . . . . . . . 68

2.3 Exercises with Their Solutions. . . . . . . . . . . . . 74

3 Analytical Methods for the Kinematic Analysis of Planar

Linkages. Raven's Method . . . . . . . . . . . . . . . . . . . . 111

3.1 Analytical Methods . . . . . . . . . . . . . . . 111

3.1 .1 Trigonometric Method . . . . . . . . . . . . 112

3.1.2 Raven's Method. . . . . . . . . . . . . . . . . . . . 112

3.1.3 Complex Mechanism Analysis. . . . . . . . . . . . . 132

3.2 Examples with Their Solutions . . . . . . . . . . . . . . 134

4 Graphical and Analytical Methods for Dynamic Analysis

of Planar Linkages. . . . . . . . . . . . . . . . . . . . . . . . . . . . . . . . . . . . . . . . . . . . . . . . . . . .

4.1 Machine Statics . . . . . . . . . . . . . . . . . . . 143

4.1.1 Force Transmission in a Mechanism. . . . . . . . . . . . 144

4.1.2 Static Equilibrium Conditions . . . . . . . . . . . . . . . 144

4.1 .3 Superposition Principle . . . . . . . . . . . . 151

4.1.4 Static Force Analysis. Graphical Method. . . . . . . . . . 154

4.2 Dynamic Analysis . . . . . . . . . . . . . . . . 158

4.2.1 Dynamic Equilibrium of a Particle with Mass . . . . . . 158

4.2.2 Inertia Components of a Link with Planar Motion . . . . 159

4.2.3 Inertial Components of a Plane Link . . . . . . . . . . . 162

4.2.4 Inertia Force Analysis in a Mechanism . . . . . . . . . . 165

4.3 Dynamic Analysis. Matrix Method. . . . . . . . . . . . . . . 174

4.4 Exercises with Solutions . . . . . . . . . . . . . . . . 189

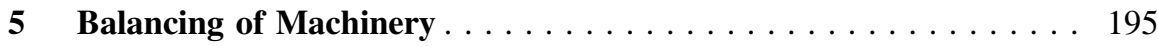

$5.1 \quad$ Rotor Balancing. . . . . . . . . . . . . . . . . . . . . . . 195

$5.1 .1 \quad$ Static Balance . . . . . . . . . . . . . . . 196

5.1 .2 Dynamic Balance. . . . . . . . . . . . . . . . . . 197

5.1.3 Analytical Method . . . . . . . . . . . . . . . . . . . . 204

5.2 Inertia Balancing of Single and Multi-cylinder Engines. . . . . . 208

5.2 .1 One-Cylinder Engines. . . . . . . . . . . . . . . 208

5.2 .2 Multi-cylinder in-Line Engines . . . . . . . . . . 218

5.3 Problems with Solutions . . . . . . . . . . . . . 227

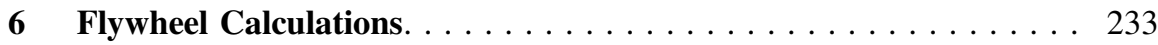

6.1 Forces and Torques in Mechanisms . . . . . . . . . . . 233

6.2 General Equation of Mechanism Motion . . . . . . . . . . . . . . 234

6.3 Working Periods of a Cyclic Machine . . . . . . . . . . 235

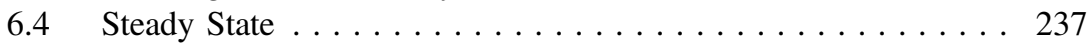

6.5 Flywheels . . . . . . . . . . . . . . . . . . . 238

6.6 Application Examples of Flywheels . . . . . . . . . . . . . 239 
6.7 Coefficient of Speed Fluctuation . . . . . . . . . . . . . 241

6.8 Design of a Flywheel . . . . . . . . . . . . . . . . . . . 242

7 Vibrations in Systems with One Degree of Freedom . . . . . . . . . . . 249

7.1 Introduction to Oscillatory Motion . . . . . . . . . . . . . . . . . 249

7.1.1 Fundamental Concepts of Vibrations . . . . . . . . . . . 249

7.1.2 Concept of Degree of Freedom (DOF) . . . . . . . . . . 251

7.1.3 Parameters of a Mechanical System . . . . . . . . . 252

7.1.4 Characterization of Oscillatory Systems . . . . . . . 253

7.1.5 Harmonic Periodic Motion: Transient and Steady-State Regimes . . . . . . . . . . . . . . 254

7.2 Single Degree of Freedom (SDOF) Systems . . . . . . . . . . . . . 255

7.2.1 Basic Discrete Model with One DOF . . . . . . . . . . 256

7.3 Free Vibrations in SDOF Systems . . . . . . . . . . . . . 257

7.3.1 Undamped Free Vibrations of SDOF Systems . . . . . . 258

7.3.2 Free Vibrations with Viscous Damping. . . . . . . . . . 264

7.4 Forced Vibrations in SDOF Systems . . . . . . . . . . . . . 268

7.4.1 Forced Vibrations with Harmonic Excitation . . . . . . . . 269

7.4.2 Harmonic Excitations in Machines . . . . . . . . . . . 273

7.4 .3 Vibration Isolation . . . . . . . . . . . . . . . 277

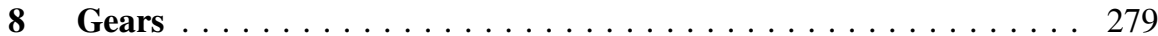

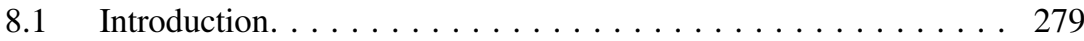

8.1.1 Characteristics of Motion Transmitted

by Curves in Contact . . . . . . . . . . . . . . . . . . 279

8.1.2 Velocity Relationship Between Two Curves

in Contact. . . . . . . . . . . . . . . . . . . . . . 280

8.1 .3 Rolling Wheels ... . . . . . . . . . . . . . . 281

8.2 Toothed Wheels (Gears) . . . . . . . . . . . . . . . . . 282

8.3 Condition for Constant Velocity Ratio. Fundamental

Law of Gearing . . . . . . . . . . . . . . . . . . . . . . . . . . 282

8.4 Involute Teeth . . . . . . . . . . . . . . . . . . . . 283

8.5 Definitions and Nomenclature . . . . . . . . . . . . . 285

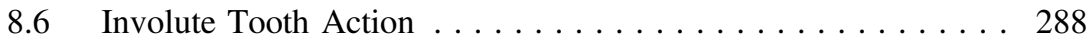

8.7 Contact Ratio . . . . . . . . . . . . . . . . . . . . . . . . . . . . . 289

8.8 Relationship Between Velocity Ratio and Base Circles . . . . . . 291

8.9 Interference in Involute Gears . . . . . . . . . . . . . . . . . . . . . . . . . . . . . . . . . . . . . . . .

8.10 Gear Classification . . . . . . . . . . . . . . . . . . . . . . . . . 294

8.10 .1 Cylindrical Gears . . . . . . . . . . . . . . . . . . . . 294

8.10 .2 Bevel Gears . . . . . . . . . . . . . . . . . . . . . . 296

8.10 .3 Hypoid Gears . . . . . . . . . . . . . . . . . . . . . 297

8.11 Manufacturing of Toothed Wheels . . . . . . . . . . . . . . . . . 297

8.12 Gear Standardization . . . . . . . . . . . . . . . . . . . 299 
8.13 Helical Gears. . . . . . . . . . . . . . . . . . . . . . . 300

8.13 .1 Helical Gear Parameters . . . . . . . . . . . . . . . . . 301

8.13.2 Correlation with Spur Gears . . . . . . . . . . . . . . 303

8.13 .3 Teeth Geometry. . . . . . . . . . . . . . . . . . . . . . . 304

8.14 Bevel Gears . . . . . . . . . . . . . . . . . . . . 305

8.14.1 Design of a Bevel Gear System . . . . . . . . . . . . . 306

8.14 .2 Bevel Gears with Straight Teeth. . . . . . . . . . . . 308

8.14 .3 Equivalent Spur Gear . . . . . . . . . . . . . . . 308

8.14.4 Teeth Geometry in Bevel Gears

with Straight Teeth. . . . . . . . . . . . . . . . . . . . . . 309

8.15 Force Analysis in Toothed Wheels . . . . . . . . . . . . . 310

8.15 .1 Forces in Spur Gears . . . . . . . . . . . . . . . 310

8.15 .2 Forces in Helical Gears. . . . . . . . . . . . . . . . . 312

8.15 .3 Forces on Bevel Gears . . . . . . . . . . . . . . . . . 313

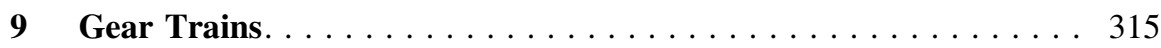

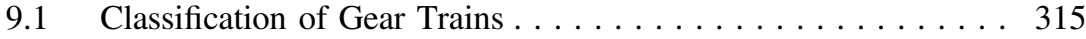

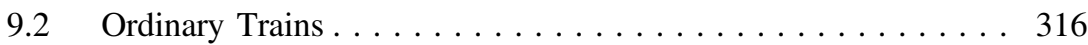

$9.2 .1 \quad$ Simple Trains . . . . . . . . . . . . . . . 316

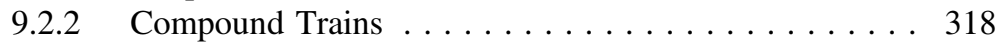

9.2 .3 Gearboxes. . . . . . . . . . . . . . . . . . . . . 319

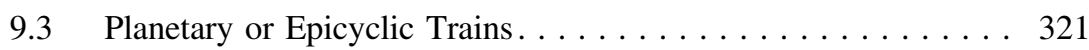

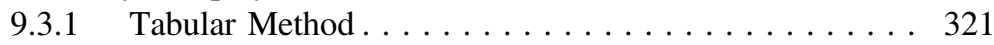

9.3.2 Formula or Algebraic Method . . . . . . . . . . . . . 323

9.3.3 Bevel Gear Differential . . . . . . . . . . . . . . . . . . 323

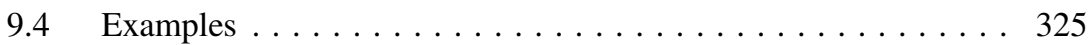

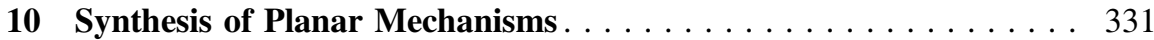

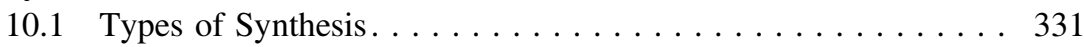

10.1.1 Structural Synthesis . . . . . . . . . . . . . . . . 332

10.1.2 Dimensional Synthesis . . . . . . . . . . . . . . 335

10.2 Function Generation Synthesis. . . . . . . . . . . . . . 337

10.2.1 Graphical Methods. . . . . . . . . . . . . . . . 338

10.2.2 Freudenstein's Method . . . . . . . . . . . . . . . . . . 340

10.3 Trajectory Generation Synthesis. . . . . . . . . . . . . . . 342

10.3.1 Graphical Methods. . . . . . . . . . . . . . . . . . . . . 343

10.3.2 Analytical Methods ... . . . . . . . . . . . . . . 345

10.4 Optimal Synthesis of Mechanisms . . . . . . . . . . . . . 350

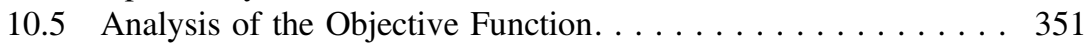

10.5.1 Function Generation Synthesis. . . . . . . . . . . 351

10.5.2 Trajectory Synthesis . . . . . . . . . . . . . . . . 352

10.6 Optimization Method Based on Evolutionary Algorithms . . . . 358 


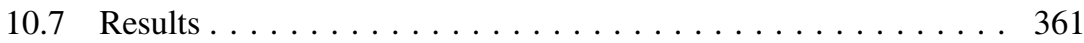

10.7.1 Closed Path Generation. . . . . . . . . . . . . . . 361

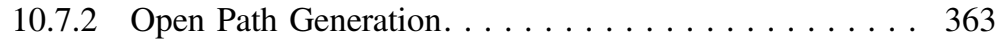

References ........................ 365

Appendix A: Position Kinematic Analysis. Trigonometric Method . . . . 367

Appendix B: Freudenstein's Method to Solve the Position Equations in a Four-Bar Mechanism . . . . . . . . . . . . . . . . 373

Appendix C: Kinematic and Dynamic Analysis of a Mechanism . . . . . 377 